\title{
Innovation in der Software Entwicklung
}

\section{Themenheft Informatik Spektrum 2021}

\section{Sven Tissot ${ }^{1}$}

Angenommen: 15. April 2021

๑) Springer-Verlag GmbH Deutschland, ein Teil von Springer Nature 2021

\section{Steve Jobs: „Stay hungry, stay foolish“ [Standford, Rede 2005]}

Muss man wirklich verrückt sein? Sind die Zeiten nicht schon verrückt genug? Die Pandemie fördert Isolation und macht den kreativen und befruchtenden Austausch untereinander nicht einfacher, wenn Kontakte ,bitte nur per VideoKonferenz" stattfinden dürfen.

Und wäre es nicht an der Zeit, sich sogar von denen zu distanzieren, die foolish sind? Noch vor einem Jahr war „Querdenken“ positiv konnotiert, doch in Zeiten von Corona leugnenden Querdenkern, Verschwörungsgedanken, Cancel Culture, Hate Speech und German Angst wird das freie Denken bzw. vorbehaltlose Disputieren und die Kommunikation über neue Ideen immer schwieriger.

Das ist schade, denn Kreativität und Innovation sind keine besonderen Begabungen Einzelner, sondern das Ergebnis von freiem Denken und dem Austausch mit Anderen und den Möglichkeiten, dies überall und jederzeit ohne Begrenzungen tun zu können.

Diese Themenheft zeigt, dass Innovation dennoch funktioniert, - auch in Zeiten von Corona. Das werden die Artikel im folgendem in vielen Ideen und Beispielen demonstrieren. Informatiker sind ja schnell als „Nerds“ oder ,Introvertierte" verschrien; nichtsdestotrotz haben gerade wir IT-Fachleute innovatives Denken in Unternehmen auch auBerhalb der Softwareindustrie und Universitäten getragen und in Zeiten von Home-Office und ,remote work“ neue Formate zum Thema Innovation und Agilität entwickelt.
Ganz herzlichen Dank an alle Autoren und Autorinnen, die dieses Themenheft mit ihren Beiträgen ermöglicht haben; und die sich auch ohne jeden persönlichen Kontakt „remote“ motivieren und begeistern haben lassen!

Software-Ingenieure und Entwickler haben schon immer für sich in Anspruch genommen, Künstler zu sein. Erinnert sei an das letzte Themenheft über digitale Kunst. Deswegen möchte ich auch heute mit einem Künstlerzitat schließen.

Konstantin Wecker, einer der bedeutendsten deutschen Liedermacher, sang: „Freiheit, des hoaßt koa Angst habn vor neamands" [Genug ist nicht genug, 1977].

In diesem Sinn: Bleiben Sie mutig, neugierig, innovativ und gesund.

Ich freue mich auf ihre Rückmeldungen

Sven Tissot

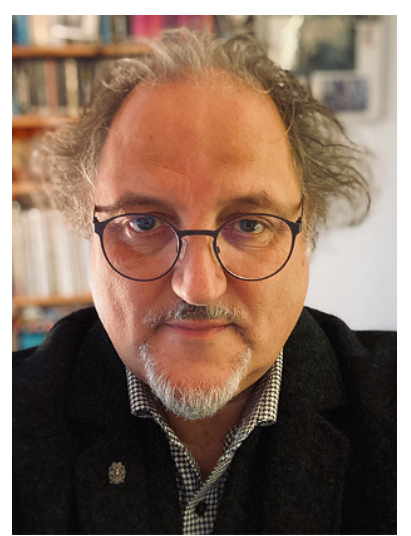

Sven Tissot

Sven Tissot

sven.tissot@iteratec.com

1 Iteratec Gmbh, Am Sandtorkai 75, 20457 Hamburg,

Deutschland 